\begin{tabular}{|c|c|}
\hline Citation & $\begin{array}{l}\text { M. Abedrabbo, F. Z. Dejene, W. Leterme and D. Van Hertem, "HVDC Grid Post-DC } \\
\text { Fault Recovery Enhancement," in IEEE Transactions on Power Delivery, June } 2020 .\end{array}$ \\
\hline Archived version & (C2020 IEEE \\
\hline \multirow[t]{2}{*}{ Published version } & DOI: $\underline{10.1109 / T P W R D .2020 .3002717}$ \\
\hline & $\begin{array}{l}\text { URL (IET Digital Library): } \\
\text { https://ieeexplore.ieee.org/document/9117162 }\end{array}$ \\
\hline Author contact & $\begin{array}{l}\text { Mudar Abedrabbo } \\
\text { mudar.abedrabbo@kuleuven.be } \\
\text { tel: }+3216323976\end{array}$ \\
\hline
\end{tabular}




\title{
HVDC Grid Post-DC Fault Recovery Enhancement
}

\author{
Mudar Abedrabbo, Graduate Student Member, IEEE, Firew Zerihun Dejene, Graduate Student Member, IEEE, \\ Willem Leterme, Member, IEEE, and Dirk Van Hertem, Senior Member, IEEE
}

\begin{abstract}
Fast and stable post-fault recovery is an essential part of a fault clearing strategy in HVDC grids. As the postfault recovery may involve de-blocking converters, unwanted oscillations may be noticed in the voltages and currents. These oscillations occur at resonant frequencies, which stem from the interaction between the converter and the grid. Methods to identify HVDC grid resonances exist, but the focus is mainly on control interactions instead of during transient conditions such as post-fault recovery. This paper provides a method to analyze oscillations during post-fault recovery process, discusses their origins and proposes two methods to mitigate these. It is found that these oscillations are mainly due to incompatibility of the converter- and grid-side DC voltage at the moment of de-blocking, and the low damping characteristic of the grid at resonant frequencies. The first mitigation approach acts on the first aspect and avoids triggering of the oscillations by matching the voltage of the converter to that of the grid at the moment of de-blocking. The second mitigation approach acts on the second aspect by increasing damping at the DC-side through controls. Time domain simulations have shown that both methods effectively reduce the oscillations seen during post-fault system recovery.
\end{abstract}

Index Terms-HVDC, modular multilevel converter (MMC), DC fault, Post-DC fault recovery.

\section{INTRODUCTION}

Voltage-Source Converter (VSC) based high voltage direct current (HVDC) grids provide the required flexibility, redundancy and reliability to the future transmission system to accommodate high penetration of renewable energy sources, bulk power transmission over long distances and connection of asynchronous AC systems [1]. At present, VSC HVDC technology is mainly used in point-to-point links besides some small multi-terminal schemes in China [2]. In a next step, these links may be interconnected to form HVDC grids, which enable power transfer at a massive scale.

In large-scale HVDC grids, fast fault interruption and fast post-fault system recovery are key factors to avoid the protracted power flow interruption. The fast DC fault interruption can be achieved using HVDC circuit breakers (DCCB) in HVDC grids with half-bridge modular multilevel converter (MMC) technology. Extensive efforts have been concentrated on developing fast DCCBs with operating times in the order of 2 to $10 \mathrm{~ms}$ [3]-[6].

The work of M. Abedrabbo was funded and supported by Mitsubishi Electric Corporation. The work of F. Z. Dejene was supported by the European Union's Horizon 2020 research and innovation programme under grant agreement No. 691714. Paper no. TPWRD-00069-2020. (Corresponding author: Mudar Abedrabbo.)

M. Abedrabbo, F. Z. Dejene, W. Leterme, D. Van Hertem are with EnergyVille/ELECTA Research Group, Electrical Engineering Department (ESAT), KU Leuven, Leuven 3001, Belgium (e-mail: mudar.abedrabbo@kuleuven.be; $\quad$ firewzerihun.dejene@kuleuven.be; willem.leterme@esat.kuleuven.be; dirk.vanhertem@esat.kuleuven.be).
The post-fault recovery process should be achieved within a short time (e.g. tens of milliseconds) to reduce the impact of DC faults on the connected $\mathrm{AC}$ systems and to restore the power flow in an adequate time. The post-fault recovery process highly depends on whether any of the converters in the HVDC grid are in the blocked state as a result of the fault. In [7], the system response after the fault is determined based on the number of converters that are in the blocked state, where three scenarios are defined, termed as HVDC grid fault-ride-through scenarios (DC-FRTS). For the first scenario (DC-FRTS1), the DCCBs are sized to avoid the blocking of the converters during DC fault conditions, while the second and third scenarios (DC-FRTS2 and DC-FRTS3) allow for temporary blocking of local and all converters, respectively [7]. Thus, the maximum power flow disturbance is mainly affected by the accepted scenario [7].

The post-fault recovery of a three-terminal two-level VSCbased HVDC grid has been studied in [8], where the authors implemented a bump-less transfer switch to reduce the overvoltages during system recovery. The power flow recovery of the half-bridge MMC has been investigated in [9], where the authors proposed a modified DQ-type circulating current suppression controller (CCSC) to improve the recovery response of the converter. The authors in [10] compared the influence of two types of CCSC on the converter recovery, and they concluded that the standard DQ-type CCSC is not suitable for post-fault recovery, while the converter recovery shows significant improvement using the CCSC proposed in [11]. In [12], the recovery process of the MMC has been analyzed and a supplementary controller is proposed to improve the damping characteristic of the MMC. An important aspect, i.e., the possible triggering of poorly damped oscillations during post-fault recovery and the mitigation thereof, has not yet been discussed in the existing literature.

The main contribution of this paper is to thoroughly investigate and enhance the post-fault recovery of HVDC grids, which provides an insight into the interactions between the converters and the HVDC grid during the recovery process, and the approaches to enhance the recovery performance of the grid. This paper discusses the origins of oscillations during post-fault recovery and their characteristics, and proposes two methods to mitigate these. The paper shows that, in the absence of countermeasures, oscillations during post-fault recovery may last for hundreds of milliseconds. This is due to the poor damping characteristic of the grid, which is moreover highly influenced by the DCCB inductors. Such oscillations may lead to unstable behavior [13] or over-voltages or overcurrents which induce stresses on equipment. The two methods proposed consist of either avoiding that the oscillations are triggered or damping the triggered oscillations through appro- 
priate control.

In this paper, an in-depth analysis is provided to efficiently and accurately predict the oscillations in the grid during the post-fault recovery process (Section II). Based on the analysis, two approaches are proposed to effectively enhance the post-fault recovery of HVDC grids (Section III), where the effectiveness of both methods are examined using a 5-terminal HVDC grid (Section IV).

\section{HVDC GRID POST-DC FAULT RECOVERY: REQUIREMENTS AND CHALLENGES}

The HVDC grid voltage and power flow must be recovered after the occurrence of a DC-side fault, as to minimize the loss of service and hence minimize the effect of the DC-side disturbance on the surrounding parts of the grid. Based on the classification of the HVDC grid fault-ride-through scenarios in [7], operating the HVDC grid during fault conditions in the second and third scenarios leads to blocking of a few or all converters, respectively. Blocking of the converters implies that they can no longer control their active powers in post-fault conditions. Consequently, converters blocking in the second scenario may cause a disturbance in the power flow, whereas converters blocking in the third scenario may lead to temporary loss of power exchange in the whole grid. To minimize the effect of these disturbances, the blocked converters must be unblocked and actively controlled as fast as possible.

The post-fault grid recovery strategy has the task to restore the DC voltage to a value close to the pre-fault value in a stable manner. This implies that the voltage (and consequently, power flow) must be recovered with an adequate speed while limiting oscillations, and avoiding over-currents and -voltages.

The capacitive and inductive components (e.g. converters, cables, line inductors, etc.) in the HVDC grid will result in resonant frequencies in the impedance spectra as seen from different parts within the grid. During switching or de-blocking of converters at voltage levels different from the grid voltage, oscillations with these resonant frequencies may be triggered. Hence, investigating the impedance spectrum of the HVDC grid seen from a de-blocked converter is essential in avoiding unwanted oscillations during the post-fault recovery process.

The impedance spectrum of the HVDC grid as seen from the converter to be de-blocked is obtained in two steps. First, the DC-side equivalent circuit of the MMC during post-fault recovery period is derived. Second, an analytical approach for HVDC grid frequency response is developed based on the nodal analysis method.

\section{A. DC-Side Equivalent Circuit of the Converter}

The interaction between the converter and the HVDC grid during the post-fault recovery can be described by the DC-side equivalent circuit. To obtain this circuit, the DC-side voltage of the converter $\left(V_{d c}(s)\right)$ can be written in terms of the DCside current $\left(I_{d c}(s)\right)$, the power balance between the $\mathrm{AC}$ and the DC sides $(\eta)$ and the zero-sequence component of the internal voltage of the converter $\left(V_{c}^{* 0}(s)\right)$, as described in (1) (derivation in Appendix A).

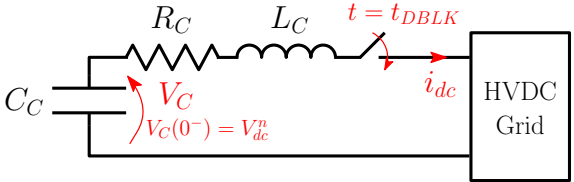

Fig. 1: DC-side equivalent circuit of HVDC converter at the instant of de-blocking.

$$
\begin{aligned}
& V_{d c}(s)=\frac{1}{6}(\frac{3 V_{d c}^{\Sigma}(0)}{s}-\underbrace{\frac{1}{s}\left\{\frac{3 N V_{s} I_{s} \cos (\phi)}{2 v_{d c} C_{s u b}}\right\}}_{\eta}+\frac{N I_{d c}(s)}{s C_{s u b}}) \\
& +\frac{2}{3} L_{\text {arm }}\left(s I_{d c}(s)-i_{d c}(0)\right)+\frac{2}{3} R_{a r m} I_{d c}(s)-\frac{1}{3} \xi V_{c}^{* 0}(s)
\end{aligned}
$$

Equation (1) shows that $V_{c}^{* 0}(s)$ plays a main role to the DCside voltage of the MMC, which is controlled by the CCSC. Different types of CCSCs are proposed in the literature [11], [14], [15]. In this section, the DQ-type circulating current suppression controller, proposed in [14], is considered for the analysis. This type is based on the double-frequency rotating negative sequence reference frame, where the $d$ and $q$ components are suppressed with a proportional-integral (PI) controller. In such an approach, the DC component of the circulating current is naturally defined by the power exchange between the converter and the grid. Hence, the zero-sequence reference of the internal voltage $\left(V_{c}^{* 0}(s)\right)$ is equal to zero in (1).

At the instant of de-blocking after fault clearance, $i_{d c}(0)$ is equal to zero, and the term $\eta$ in (1) can be ignored, under the assumption of zero power exchange between the $\mathrm{AC}$ and DC sides at the instant of de-blocking. Hence, (1) can be simplified as shown in (2), where $V_{d c}^{\Sigma}(0)$ is assumed to be equal to twice the nominal DC voltage $\left(2 V_{d c}^{n}\right)$.

$$
\begin{aligned}
V_{d c}(s) & =Z_{C_{i}}^{d c} I_{d c}(s)+\frac{V_{d c}^{n}}{s}, \\
\text { where } Z_{C_{i}}^{d c} & =s L_{C_{i}}+R_{C_{i}}+\frac{1}{s C_{C_{i}}}, \\
L_{C_{i}} & =\frac{2}{3} L_{a r m}, R_{C_{i}}=\frac{2}{3} R_{a r m}, C_{C_{i}}=\frac{6 C_{s u b}}{N}
\end{aligned}
$$

Based on (2), the DC-side equivalent circuit of the converter at the instant of de-blocking with zero power exchange is an $R L C$ circuit with a precharged capacitor voltage of $V_{d c}^{n}$ as shown in Fig. 1, where $V_{d c}^{n}$ is the pole-to-pole voltage in symmetrical monopolar configuration, and pole-to-ground voltage in asymmetrical monopolar and bipolar configurations. This $R L C$ equivalent circuit is switched-in at the instant of de-blocking. It is important to note that this assumption is valid at the instant of de-blocking after fault clearance, while the mismatch between the DC-side behavior of the converter and the $R L C$ circuit behavior increases over time after deblocking, due to the contribution of the power balance term $\eta$ in (1). The influence of this term depends on the bandwidth of the outer controllers.

The recovery process of the converter, represented by switching-in the $R L C$ equivalent circuit, triggers electromag- 


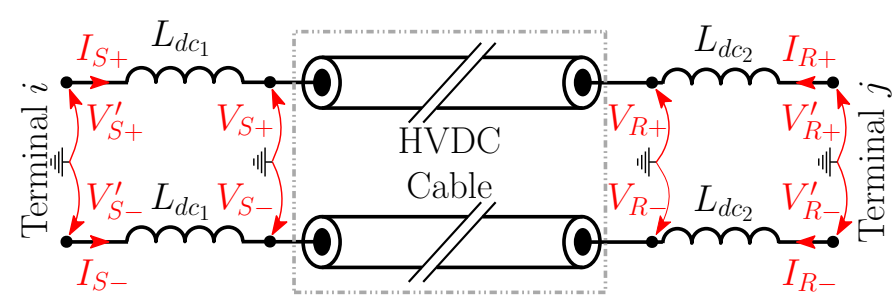

Fig. 2: HVDC cable system terminated by line inductors.

netic oscillations in case the voltage of the grid is not equal to $V_{d c}^{n}$ at the moment of switching.

\section{B. DC-side Resonance Analysis of HVDC Grids}

This section presents an analytical approach to calculate the frequency response of the HVDC grid and to find the DC-side resonant frequencies. It uses the nodal analysis method and the equivalent circuit of the MMC developed in the previous section.

Using the nodal analysis method, the HVDC grid can be described using an admittance matrix $\mathbf{Y}_{\mathbf{D C}}$, which relates the vector of currents injected at each node $\mathbf{I}$ to the vector of voltages at each node $\mathbf{V}$, i.e. $\mathbf{I}=\mathbf{Y}_{\mathbf{D C}} \mathbf{V}$.

The HVDC grid admittance matrix $\left(\mathbf{Y}_{\mathbf{D C}}\right)$ is obtained in two steps. First, the admittance matrix of the cable system terminated by line inductors is derived. Second, the cable system admittance matrix and the DC-side equivalent circuit of the converter are used to derive the HVDC grid admittance matrix.

1) Admittance matrix of HVDC cable system terminated by line inductors: The sending- and receiving-end currents vector of the multi-pole HVDC cable system shown in Fig. 2 can be written in terms of terminal voltages vector, i.e. $\mathbf{V}_{\mathbf{S}}$ and $\mathbf{V}_{\mathbf{R}}$, as derived in (3), where $\mathbf{Y}_{\mathbf{T L}}$ is the admittance matrix of the HVDC cable system. The sub-matrices of $\mathbf{Y}_{\mathbf{T L}}$ are given in (4) [16]. The characteristic impedance matrix $\left(\mathbf{Z}_{\mathbf{c}}\right)$ is equal to $\gamma^{-1} \mathbf{Z}$, where $\gamma$ is the propagation constant matrix $(\sqrt{\mathbf{Z Y}})$, $\mathbf{Z}$ is the impedance matrix and $\mathbf{Y}$ is the admittance matrix of the cable system.

$$
\begin{aligned}
{\left[\begin{array}{c}
\mathbf{I}_{\mathbf{S}} \\
\mathbf{I}_{\mathbf{R}}
\end{array}\right] } & =\underbrace{\left[\begin{array}{cc}
\mathbf{Y}_{\mathbf{S}} & -\mathbf{Y}_{\mathbf{m}} \\
-\mathbf{Y}_{\mathbf{m}} & \mathbf{Y}_{\mathbf{S}}
\end{array}\right]}_{\mathbf{Y}_{\mathrm{TL}}}\left[\begin{array}{c}
\mathbf{V}_{\mathbf{S}} \\
\mathbf{V}_{\mathbf{R}}
\end{array}\right] \\
\mathbf{Y}_{\mathbf{s}} & =\mathbf{Z}_{\mathbf{C}}^{-1} \operatorname{csch}(\gamma l) \cosh (\gamma l) \\
\mathbf{Y}_{\mathbf{m}} & =\mathbf{Z}_{\mathbf{C}}^{-1} \operatorname{csch}(\gamma l)
\end{aligned}
$$

The admittance matrix of the HVDC cable system terminated by line inductors $\left(\mathbf{Y}_{\mathbf{L}_{\mathbf{i j}}}\right)$ is synthesized from the admittance matrices of the basic sections (i.e. line inductors and HVDC cable system), which can be found by eliminating the internal nodes using Gauss-Rutishauser/Kron elimination method [17] as given in (5), where the sub-matrices $\mathbf{Y}_{\mathbf{1 1}}$ and $\mathbf{Y}_{22}$ are described in (6).

$$
\left[\begin{array}{c}
\mathbf{I}_{\mathbf{S}} \\
\mathbf{I}_{\mathbf{R}}
\end{array}\right]=\underbrace{\left[\mathbf{Y}_{11}-\mathbf{Y}_{11} \mathbf{Y}_{\mathbf{2 2}}^{-1} \mathbf{Y}_{11}\right]}_{\mathbf{Y}_{\mathbf{L}_{\mathrm{ij}}}}\left[\begin{array}{c}
\mathbf{V}_{\mathbf{S}}^{\prime} \\
\mathbf{V}_{\mathbf{R}}^{\prime}
\end{array}\right]
$$

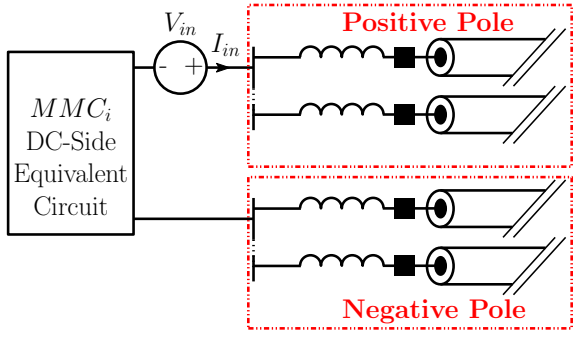

Fig. 3: DC-side equivalent impedance seen by MMC.

$$
\begin{gathered}
\mathbf{Y}_{\mathbf{1 1}}=\left[\begin{array}{cc}
\mathbf{Y}_{\mathbf{L}_{\mathbf{i n}}} & \mathbf{0} \\
\mathbf{0} & \mathbf{Y}_{\mathbf{L}_{\text {out }}}
\end{array}\right], \mathbf{Y}_{\mathbf{2 2}}=\left[\begin{array}{cc}
\mathbf{Y}_{\mathbf{L}_{\text {in }}}+\mathbf{Y}_{\mathbf{s}} & -\mathbf{Y}_{\mathbf{m}} \\
-\mathbf{Y}_{\mathbf{m}} & \mathbf{Y}_{\mathbf{L}_{\text {out }}}+\mathbf{Y}_{\mathbf{s}}
\end{array}\right], \\
\text { where } \mathbf{Y}_{\mathbf{L}_{\mathbf{i n}}}=\left[\begin{array}{cc}
\frac{1}{s L_{d c_{1}}} & 0 \\
0 & \frac{1}{s L_{d c_{1}}}
\end{array}\right], \mathbf{Y}_{\mathbf{L}_{\text {out }}}=\left[\begin{array}{cc}
\frac{1}{s L_{d c_{2}}} & 0 \\
0 & \frac{1}{s L_{d c_{2}}}
\end{array}\right]
\end{gathered}
$$

2) Admittance matrix of HVDC Grids: The admittance matrices of the transmission line and the converter in (5) and (7), respectively, are the building-blocks of the admittance matrix of the HVDC grid $\left(\mathbf{Y}_{\mathbf{D C}}\right)$. The admittance matrix ( $\left.\mathbf{Y}_{\mathbf{D C}}\right)$ can be generated by following the approach described in [18].

$$
\mathbf{Y}_{\mathbf{C}_{\mathbf{i}}}^{\mathbf{m}}=\left[\begin{array}{cc}
Y_{C_{i}} & -Y_{C_{i}} \\
-Y_{C_{i}} & Y_{C_{i}}
\end{array}\right], \text { where } Y_{C_{i}}=\frac{1}{Z_{C_{i}}^{d c}}
$$

3) DC-side resonance analysis of HVDC grids: The nodal equation of the HVDC grid can be rewritten as (8), where $\mathbf{I}_{\mathbf{i}}$ is the current injection vector at the positive and negative terminals of the $i^{\text {th }}$ converter (MMC $i$ in Fig. 3).

$$
\left[\begin{array}{c}
\mathbf{I}_{\mathbf{i}} \\
\hline \mathbf{I}_{\mathbf{r}}
\end{array}\right]=\left[\begin{array}{c|c}
\mathbf{Y}_{\mathrm{ii}} & \mathbf{Y}_{\mathrm{ir}} \\
\hline \mathbf{Y}_{\mathrm{ri}} & \mathbf{Y}_{\mathrm{rr}}
\end{array}\right]\left[\begin{array}{c}
\mathbf{V}_{\mathbf{i}} \\
\hline \mathbf{V}_{\mathbf{r}}
\end{array}\right]
$$

By considering current injection at the bus of $M M C_{i}$ only (as in Fig. 3), the system can be reduced to (9) by applying Gauss-Rutishauser/Kron elimination method.

$$
\left[\mathbf{I}_{\mathbf{i}}\right]=\underbrace{\left[\mathbf{Y}_{\mathbf{i i}}-\mathbf{Y}_{\mathbf{i r}} \mathbf{Y}_{\mathbf{r r}}^{-1} \mathbf{Y}_{\mathbf{r i}}\right]}_{\mathbf{Y}_{\mathbf{i}}}\left[\mathbf{V}_{\mathbf{i}}\right]
$$

The DC-side equivalent impedance with respect to $M M C_{i}$ can be found by (10), where $\left|\mathbf{Y}_{\mathbf{i}}\right|$ is the determinant of $\mathbf{Y}_{\mathbf{i}}$ in (9) and $Y_{i}(n)$ is the $n^{t h}$ element of $\mathbf{Y}_{\mathbf{i}}$.

$$
\frac{V_{i n}}{I_{i n}}=Z_{D C}=\frac{\left|\mathbf{Y}_{\mathbf{i}}\right|}{Y_{C_{i}}\left(\left|\mathbf{Y}_{\mathbf{i}}\right|-Y_{C_{i}} \sum_{n=1}^{4} Y_{i}(n)\right)}
$$

By investigating the behavior of the DC-side equivalent impedance $\left(Z_{D C}\right)$ in the frequency domain, the resonant frequencies and damping characteristic of the HVDC grid seen by $M M C_{i}$ can be found.

\section{HVDC SYSTEM RECOVERY ENHANCEMENT}

In this section two approaches to enhancing the postfault recovery process are proposed. The objective of the approaches is to restore the DC voltage and power flow such that oscillations are mitigated. 


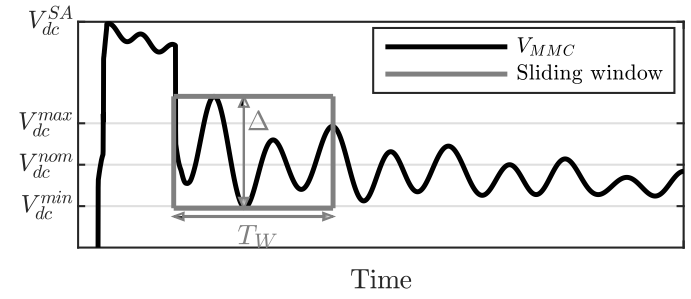

Fig. 4: Illustrative example of DC-side voltage profile at converter terminal during fault clearance (blocked converter), where $V_{d c}^{S A}$ is the voltage rating of the surge arrester.

\section{A. Voltage Matching Method}

1) DC-side voltage evaluation criterion: This approach avoids triggering oscillations by timing the instant of converter de-blocking, i.e., by switching-in the converter at the moment at which the converter DC voltage matches the HVDC grid voltage. The challenge with this approach stems from the fact that, after fault clearance, the HVDC grid voltage consists of a DC component in addition to oscillatory components. The latter are due to the rapid increase of the DC-side voltage as a consequence of isolation of the faulty line/component as shown in Fig. 4. The frequencies of these oscillations are determined by the resonant frequencies of the grid.

In this approach, the instant of converter de-blocking is based on a DC-side voltage evaluation criterion. The DCside voltage evaluation criterion proposed in this paper detects when the oscillations superimposed on the DC voltage are sufficiently damped for de-blocking and whether the DC-side voltage lies close to the nominal value. The damping of the oscillations is assessed by calculating their peak-to-peak value and comparing these with a threshold. The proposed voltage evaluation criterion acts as follows: The DC-side voltage is sampled at a frequency of $f_{s}$ within a sliding window of length $T_{W}$ (indicated by the gray box in Fig. 4). Based on the samples within this window, the instant of converter deblocking is considered suitable when the following conditions are met:

- The peak-to-peak value of the oscillation ( $\Delta$ in Fig. 4 ) is less than a pre-defined threshold $X_{1}$ (i.e. DC-side voltage settling value, which can be for example set to $5 \%, 10 \%$ or $15 \%$ of the nominal DC voltage).

- The instantaneous pole-to-pole voltage lies between highest and lowest limits (i.e. $V_{d c}^{\min }<V_{d c}<V_{d c}^{\max }$ in Fig. 4).

- The instantaneous DC terminal current of the converter is zero.

The sampling frequency of the DC-side voltage evaluation criterion should be at least twice the highest resonant frequency of the grid, while the time window length $\left(T_{W}\right)$ should be selected based on the lowest resonant frequency. The resonant frequencies are highly influenced by the line inductor values, the number of blocked converters and the change in the grid topology (e.g. disconnection of the transmission lines and converters outages due to faults or maintenance, or grid expansion). Hence, all possible scenarios should be investigated to determine the maximum and minimum resonant frequencies to determine the minimum sampling frequency and the time window length.

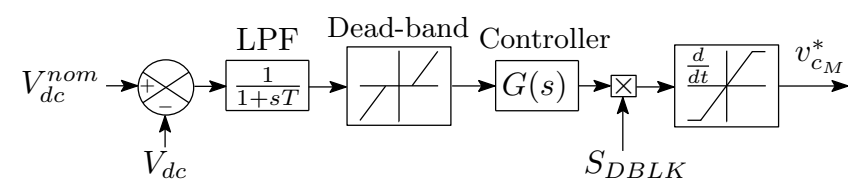

Fig. 5: DC-side voltage matching control loop.

2) DC-side voltage reduction controller: In the case that the post-fault DC-side voltage remains permanently below the minimum value ( $V_{d c}^{\min }$ in Fig. 4), the grid-side and converter DC-side voltage may not be matched using the existing controls and the voltage evaluation criterion. In such a case, the converter DC-side output voltage should be matched with the grid-side DC voltage at the instant of de-blocking. The voltage matching can be achieved by reducing the number of inserted submodules at the instant of de-blocking, such that the converter DC-side voltage is reduced to a value close to the grid-side voltage.

To reduce the number of submodules at the instant of deblocking, an additional controller is proposed. The proposed controller (shown in Fig. 5) is similar to the concept of submodules reduction proposed in [19]. The proposed controller reduces the number of submodules at the instant of deblocking by subtracting the output of the control loop from the internal voltage reference. The controller is only activated at the de-blocking instant, by means of the signal $S_{D B L K}$. To limit the rate of change of the number of submodules, a rate limiter is applied. The rate limiter reduces the number of submodules as fast as possible, whereas it puts a limit on the increase rate of inserted number of submodules until the nominal DC-side voltage is reached. The voltage error (i.e. the difference between the nominal DC voltage and grid voltage) is fed into a controller $(G(s)$ ) to adjust the system response at the instant of de-blocking. A proportional controller can be enough to regulate the DC-side voltage, and the low-pass filter is added to filter-out undesired high frequency components.

During normal operation, the output of the controller is set to zero by the dead-band block, as the DC-side voltage is close to the nominal value. If the DC-side voltage at the instant of de-blocking is lower than $V_{d c}^{\min }$, where the error falls outside the predefined dead-band, the controller output reduces the inserted submodules to match the grid voltage.

\section{B. CCSC Requirements for Recovery Enhancement}

As discussed, converter de-blocking may generate uncontrolled oscillations. The magnitudes of these oscillations depend on the damping characteristic of the grid, unless the converter controllers are able to control and suppress a wide range of non-DC component frequencies. This section discusses the requirements of the CCSC to suppress the non-DC components, and proposes a modification to the standard DQtype CCSC to improve the system recovery.

As concluded from (1), the zero-sequence component of the internal voltage, i.e. $V_{c}^{* 0}(s)$, plays a main role to the DCside voltage of the MMC. This component can be managed by controlling the zero-sequence component of the circulating current. Hence, the CCSC, which acts on suppressing the second harmonic only (e.g. standard DQ-type CCSC), does 


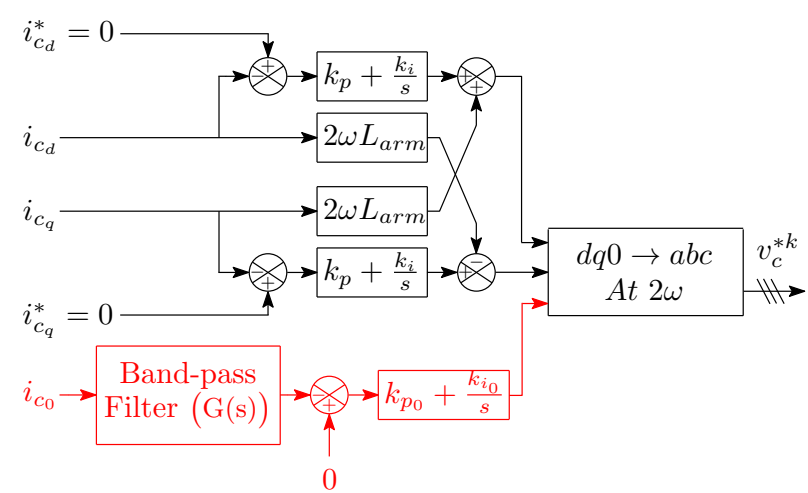

Fig. 6: Modified DQ-type CCSC.

not influence other components (as shown in Section II-A, this type reduces the DC-side equivalent circuit of the MMC to an $R L C$ circuit, where the damping characteristic is solely determined by the grid). Whereas, the CCSC, which controls the DC and AC components of the circulating current, adds $V_{c}^{* 0}(s)$ to the internal voltage reference. By following this control approach, the damping characteristic of the converter can be improved, and consequently, the post-fault recovery.

The proposed circulating current control approaches in [11] and [20] achieve the aforementioned requirement. They aim to suppress the AC components in the circulating current by resonant controllers, while its DC component is regulated by $\mathrm{P}$ or PI controllers. The reference value of the DC component is calculated using the power balance between the AC and DC sides.

The standard DQ-type CCSC can be modified also to improve the damping characteristic without influencing the steady-state DC current. The steady-state DC component of the circulating current is naturally defined by the power exchange between the converter and the grid. The proposed modification, as shown in red in Fig. 6, suppresses the zero-sequence nonDC components of the circulating current.

During post-fault recovery, non-DC components enter the zero-sequence component ( $i_{c_{0}}$ in Fig. 6), which ideally contains only a DC component during steady-state operation. To suppress these non-DC components in the zero-sequence current, a band-pass filter is used to isolate them from the DC component and a PI controller is used to control them to zero. The bandwidth of the band-pass filter should be wide enough to cover the range of resonant frequencies, which are found by the DC-side resonance analysis (Section II-B).

Unlike the standard DQ-type CCSC, the modified DQ-type CCSC adds a zero-sequence component to the internal voltage reference $\left(V_{c}^{* 0}(s)\right)$, which is obtained from the zero-sequence control loop output of the circulating current. This component can be found by (11), where $G(s)$ is the transfer function of the band-pass filter. Consequently, (1) can be rewritten as (12), under the assumption of zero power exchange between the AC and DC sides at the instant of de-blocking.

$$
V_{c}^{* 0}(s)=-G(s)\left(k_{p}+\frac{k_{i}}{s}\right) i_{c_{0}}(s)
$$

$$
\begin{gathered}
V_{d c}(s)=Z_{C}^{d c} I_{d c}(s)+\frac{V_{d c}^{n}}{s}, \\
\text { where } Z_{C}^{d c}=s L_{C}+R_{C}+\frac{1}{s C_{C}}+\underbrace{\frac{2}{3} G(s)\left(k_{p}+\frac{k_{i}}{s}\right)}_{\Psi}
\end{gathered}
$$

Based on (12), the DC-side equivalent circuit of the converter at the instant of de-blocking with zero power exchange is an $R L C$ circuit with a pre-charged capacitor voltage of $V_{d c}^{n}$ in addition to the term $\Psi$, which can improve the response of the converter during transients by providing damping to non-DC currents, that can be generated due to the post-fault recovery. The required damping can be achieved by selecting the suitable parameters of $\Psi$.

It is important to note that the proposed modification is an alternative to the proposals in [11] and [20], where these methods may provide similar damping characteristic during post-fault recovery. Additional investigations should be carried out to compare the various types of CCSC and their influence on the system performance during transients and steady-state conditions.

\section{CAse Study}

The 5-terminal meshed HVDC grid test system shown in Fig. 7 is used for validation purposes. The HVDC grid, which has symmetrical monopolar configuration, connects different $\mathrm{AC}$ systems via the half-bridge MMCs $\mathrm{A}, \mathrm{B}, \mathrm{C}, \mathrm{D}$ and $\mathrm{E}$. The parameters of the HVDC converters and their associated AC systems are listed in Table I. The parameters and configurations of the frequency dependent cable model are given in Table III and in Fig. 20 in Appendix B.

All MMCs in the grid are modeled following the approach outlined in [21], where the direct voltage control method is used to generate the modulation indices of the upper and lower arms [20], in combination with a DQ-type CCSC to suppress the parasitic components in the arm voltages [20]. The converter internal protection consists of over-current protection. The over-current protection operates and blocks the converter when the current in any arm exceeds $140 \%$ of the maximum continuous current of the IGBTs.

In Section IV-A, the DC-side equivalent circuit of the converter at the instant of de-blocking and the DC-side resonance analysis as introduced in Section II are verified by means of frequency scans in an EMT-type tool. In Section IV-B, the DC-side equivalent circuit of the converter at the instant of deblocking and the HVDC grid recovery performance enhancement provided by the proposed methods are demonstrated using time domain simulations.

\section{A. Frequency Domain Validation}

1) Validation of DC-Side equivalent circuit of the converter: To validate the DC-side equivalent circuit of the converter in the frequency domain, a frequency scan of an 800 MVA converter in EMT-type tool (e.g. PSCAD) is used as an illustrative example. An AC voltage source $\left(V_{i n}\right)$ is connected to the DC-side of the converter, to inject an AC current 


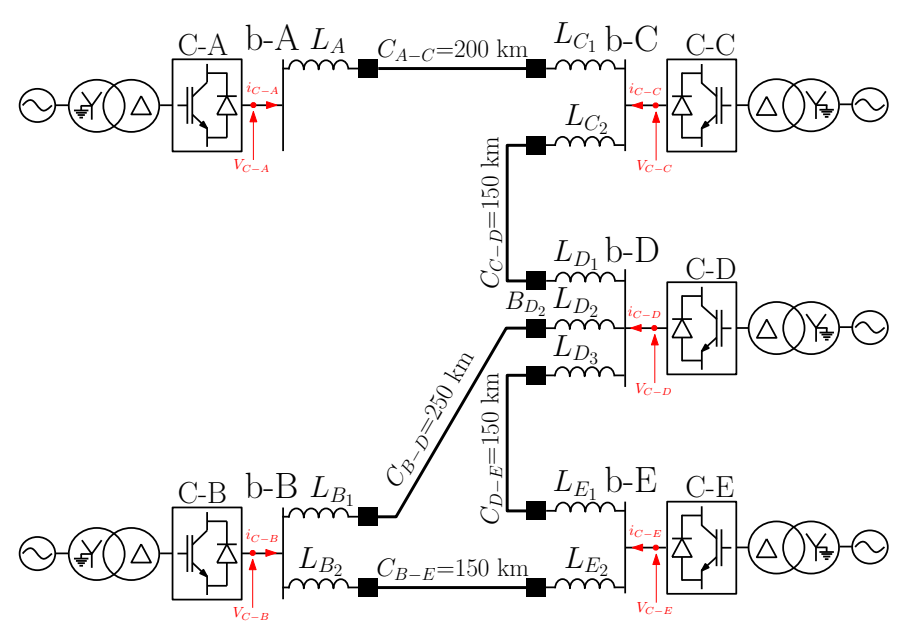

Fig. 7: 5-terminal meshed HVDC grid test system. The measurement points are indicated in red, where $i_{C-A}, i_{C-B}$, $i_{C-C}, i_{C-D}$ and $i_{C-E}$ are the positive pole DC-side currents of the converters, while $V_{C-A}, V_{C-B}, V_{C-C}, V_{C-D}$ and $V_{C-E}$ are the pole-to-pole DC-side voltages.

TABLE I: Parameters of HVDC grid test system.

\begin{tabular}{llllll}
\hline Parameters & A & B & C & D & E \\
\hline DC voltage [kV] & $\pm 320 \pm 320$ & & $\pm 320 \pm 320$ & \pm 320 \\
Converter capacity [MVA] & 800 & 800 & 400 & 800 & 600 \\
Transformer leakage reactance $[\mathrm{pu}]$ & $18 \%$ & $18 \%$ & $18 \%$ & $18 \%$ & $18 \%$ \\
Transformer series resistance $[\mathrm{pu}]$ & $0.6 \%$ & $0.6 \%$ & $0.6 \%$ & $0.6 \%$ & $0.6 \%$ \\
MMC arm reactance $[\mathrm{pu}]$ & $15 \%$ & $15 \%$ & $15 \%$ & $15 \%$ & $15 \%$ \\
MMC arm capacitance $[\mu F]$ & $98 \quad 98$ & 40 & 78 & 59 \\
Control mode & $\mathrm{P}-V_{d c}^{\text {droop }} \& \mathrm{Q}$ & \multicolumn{3}{c}{$\mathrm{P} \& \mathrm{Q}$} \\
\hline
\end{tabular}

$\left(I_{i n}\right)$. The resulting AC current is measured for different frequencies and the equivalent impedance of the converter can be estimated [22].

The frequency response as obtained from the $R L C$ equivalent circuit shows a good agreement with the results obtained using the EMT-type software (Fig. 8). Fig. 8 compares the frequency response of the DC-side equivalent circuit as obtained from (2) (black line) with the frequency response of the converter as obtained from EMT-type software (blue markers).

The modified DQ-type CCSC improves the DC-side frequency response of the converter (Fig. 8). A comparison between the frequency response of the converter with the modified DQ-type CCSC using (12) (green dashed-line) and the simulation approach (red markers) is shown in Fig. 8. The center frequency of the band-pass filter is $30 \mathrm{~Hz}$ (i.e. the resonant frequency of the investigated converter). It is clear from the results that the magnitude of the DC-side equivalent impedance of the converter is increased dramatically at the resonant frequency $(30 \mathrm{~Hz})$ when the modified CCSC is activated, which would improve the damping characteristic of the converter.

2) Validation of $D C$-side resonance analysis: The equivalent DC-side circuit of the MMCs in Fig. 7 is used to validate the suitability of the equivalent circuit for the DCside resonance analysis. The DC-side resonance is investigated using the system shown in Fig. 7 with respect to C-D as an
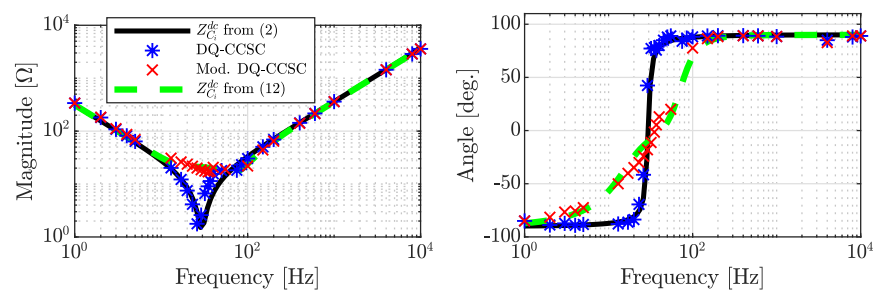

Fig. 8: Frequency response of MMC DC-side impedance.

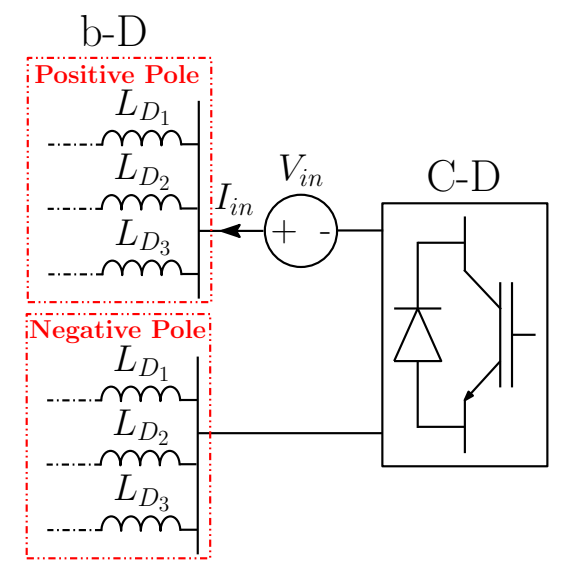

Fig. 9: General arrangement to investigate the frequency response of the HVDC grid in EMT-type software.

illustrative example. The line inductor value is limited to $1 \mathrm{mH}$ for the following reasons:

1) To focus on the MMC circuits in the validation of the DC-side resonance analysis.

2) To show that the DC-side resonance analysis is still valid even with very low line inductor values, as it is expected in non-selective protection strategy to use very low line inductor value (few $\mathrm{mH}$ [23]), where no HVDC circuit breakers are implemented (e.g. clearing the fault using ACCB).

The frequency response of the test system is investigated using two approaches:

- The test system is simulated in EMT-type software to investigate the frequency response of the system. A variable frequency voltage source with an amplitude of $64 \mathrm{kV}$ ( $10 \%$ of the pole-to-pole voltage) is connected to the DC terminal of the converter under investigation (i.e. C-D) as shown in Fig. 9. The injected current is measured for various frequencies. The frequency response of the HVDC grid seen from the converter under investigation can be found by dividing the input voltage $V_{i n}$ by the input current $I_{\text {in }}$ in the frequency domain.

- The analytical approach described in Section II-B is used to obtain the grid equivalent impedance $Z_{D C}$ using (10).

The frequency response as obtained using the analytical approach shows a very good agreement with the results obtained using the EMT-type software (Fig. 10). A comparison between the magnitude and phase results of $Z_{D C}$ using the analytical and the simulation approaches is shown in Fig. 10, where the resonant frequencies and the damping characteristic can be extracted. 

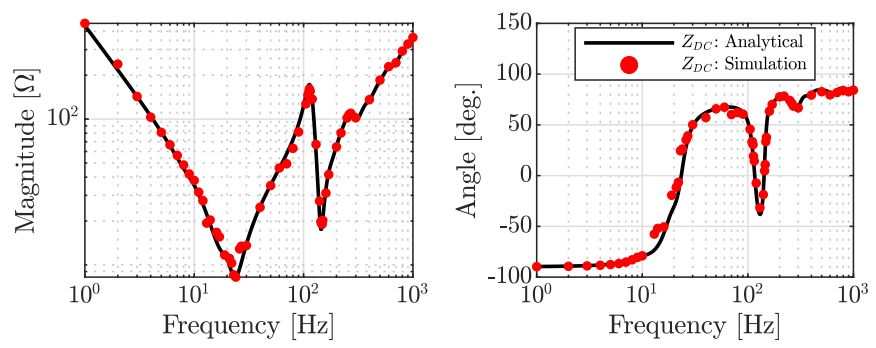

Fig. 10: Frequency response of the HVDC grid in Fig. 7 from C-D side, with $1 \mathrm{mH}$ line inductor value.

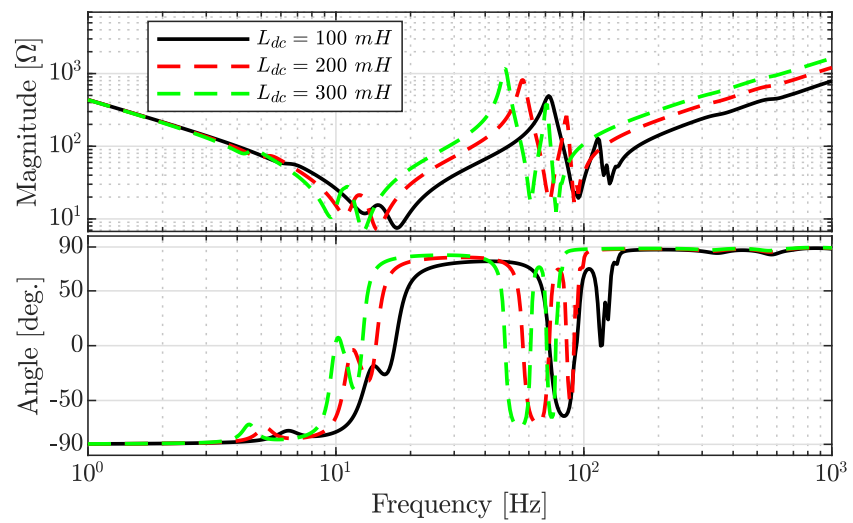

Fig. 11: Frequency response of the HVDC grid from C-D side, with 100, 200, $300 \mathrm{mH}$ inductors.

The line inductor value influences the frequency response of the HVDC grid (Fig. 11). It is obvious from Fig. 11 that increasing the line inductor value reduces the resonant frequencies and the magnitude of the equivalent impedance (i.e. the damping characteristic of the grid), which agrees with the conclusion in [13]. As the cable resistance decreases with decreasing frequencies, an increase in the series inductance results in oscillations which are less damped. It is also important to note that the line inductor value influences the voltage evaluation criterion (Section III-A1) in two ways: (a) by affecting the sliding window length $\left(T_{W}\right)$, as $T_{W}$ is determined based on the lowest resonant frequency in the grid, where the reduction in the line inductor value reduces $T_{W}$, (b) by affecting the damping characteristic of the grid, and consequently, the decay of DC voltage oscillations after fault clearance is influenced.

The number of blocked converters influences the frequency response of the HVDC grid as shown in Fig. 12, which shows the magnitude and phase of the HVDC grid equivalent impedance for the following scenarios as illustrative examples:

1) All converters are unblocked (black line in Fig. 12).

2) All converters are blocked (red-dashed line in Fig. 12).

3) Converters $\mathrm{C}-\mathrm{A}$ and $\mathrm{C}-\mathrm{C}$ are unblocked (gray-dashed line in Fig. 12).

Moreover, different impedance spectra are seen by different converters, which result in different resonant frequencies and damping characteristics. Fig. 13 shows the impedance spectra of the HVDC grid from C-A, C-B, C-C, C-D and C-E sides when $C_{B-D}$ is disconnected, where the impedance spectrum seen by converter $\mathrm{C}-\mathrm{A}$ has the highest magnitude, while the lowest impedance magnitude is seen by converter C-E.

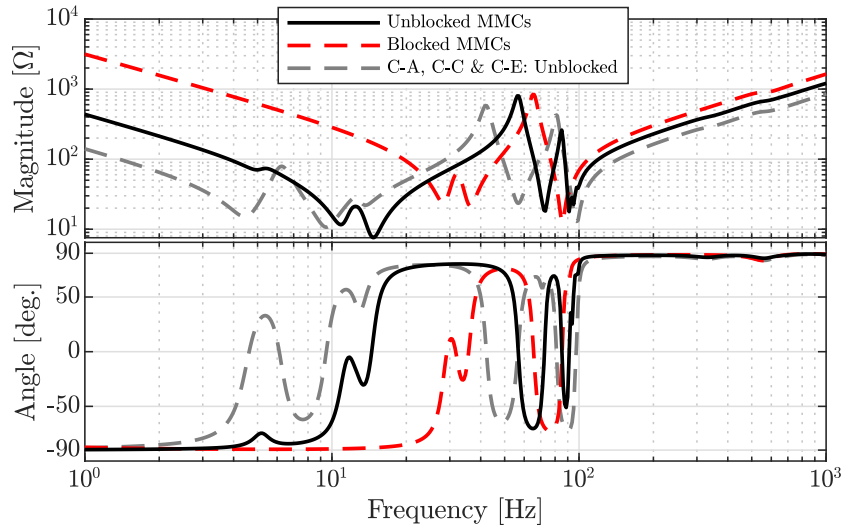

Fig. 12: Frequency response of the HVDC grid from C-D side with different number of blocked converters, where the line inductor value is $200 \mathrm{mH}$.

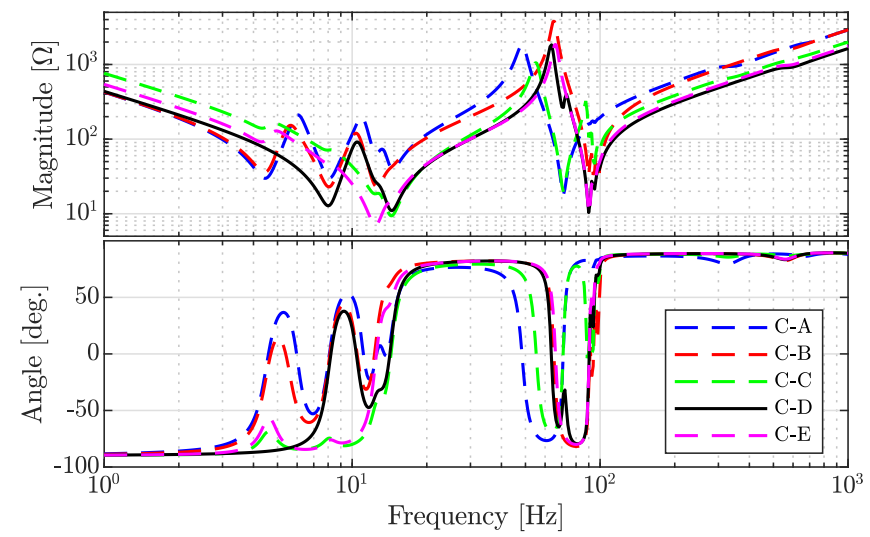

Fig. 13: Frequency response of the HVDC grid seen from different converters, where the line inductor value is $200 \mathrm{mH}$ and $C_{B D}$ is disconnected.

\section{B. Time Domain Validation}

1) Validation of DC-side equivalent circuit of the converter: To validate the DC-side equivalent circuit, converter C-B with cable $C_{B-D}$ is used as an illustrative example. The cable is charged to $540 \mathrm{kV}$ before the de-blocking of the converter, while the submodule capacitors are charged to the nominal voltage (i.e. $v_{c}^{\Sigma k}(0)=V_{d c}^{n}=640 \mathrm{kV}$ ). The time domain response of the DC-side equivalent circuit (obtained through Numerical Inverse Laplace Transform) matches well with the time domain response of the detailed simulation model, for small as well as large series inductor values (Fig. 14).

2) Validation of post-fault HVDC grid recovery enhancement methods: To validate the post-fault HVDC recovery enhancement, six cases are investigated. In these cases, a DCside fault is applied in cable $C_{B-D}$ at zero distance from bus b-D. The faults are cleared by means of DCCB with an $8 \mathrm{~ms}$ operating time and a series inductor of $200 \mathrm{mH}$. The third fault-ride-through scenario as defined in [7] is considered, which allows all converters in the grid to temporarily block during DC faults. As a consequence of this scenario, all converters lose the ability of controlling the DC voltage/power in addition to the power flow loss on the HVDC grid during and after fault clearance. In all cases, the pre-fault situation, CD is injecting $800 \mathrm{MW}$ to the HVDC grid and C-B is injecting 

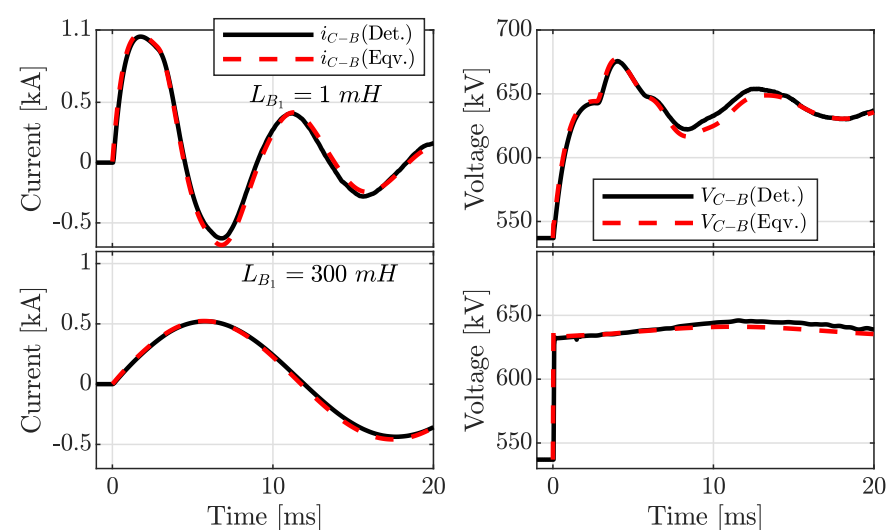

Fig. 14: Voltage measured at $\mathrm{b}-\mathrm{B}$ and current injected by converter $\mathrm{B}$ for a detailed model of $\mathrm{C}-\mathrm{B}$ and its equivalent circuit for two line inductor values.
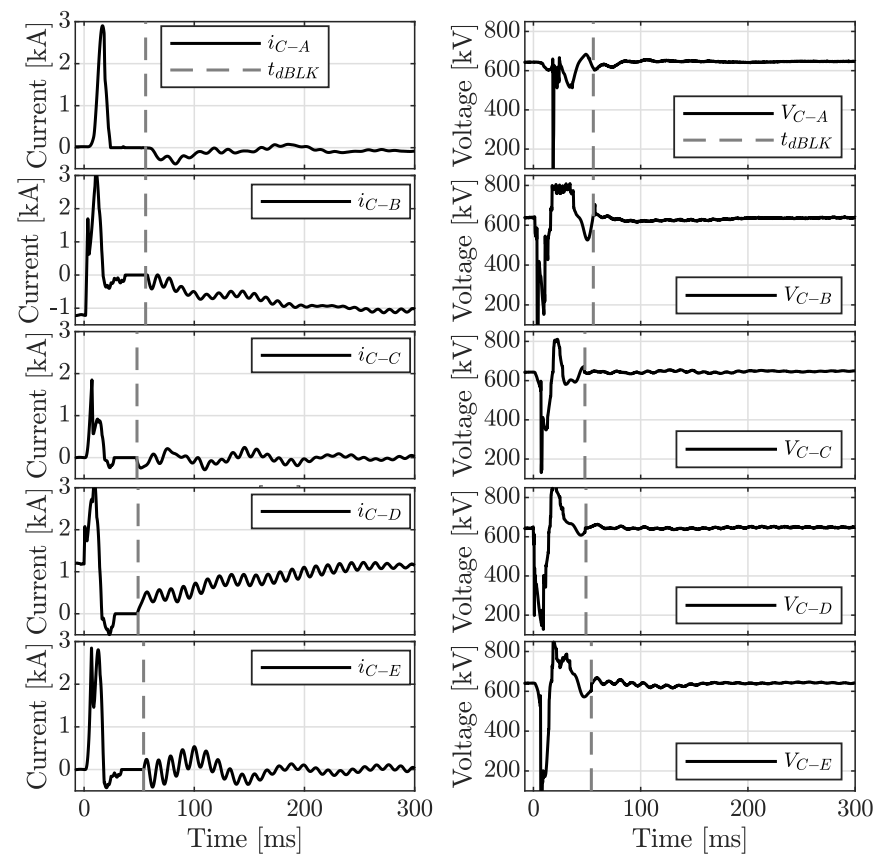

Fig. 15: Post-fault recovery performance of all converters for Case 1.

$800 \mathrm{MW}$ to the AC grid. Following cases are studied:

Case 1: Converters are de-blocked $20 \mathrm{~ms}$ after fault clearance. The fault is considered cleared when the DC terminal voltage is higher than $80 \%$ and zero DC terminal current. In this case, none of the proposed methods are activated. Fig. 15 shows the DC-side current and voltage waveforms of all converters in Fig. 7.

The time domain simulation results in Fig. 15 show that the oscillations frequencies are in a very good agreement with the resonant frequencies in Fig. 13, where Table II summarizes and compares the oscillations frequencies extracted from the DC-side current waveforms in Fig. 15 and the resonant frequencies shown in Fig. 13.

Case 2: Converters are de-blocked based on the voltage evaluation criterion. The length of the sliding time window of the voltage evaluation criterion is set to $77 \mathrm{~ms}$, based on the lowest resonant frequency with the lowest magnitude in the system of Fig. 7, which is $13 \mathrm{~Hz}$ (see Fig. 13),
TABLE II: Comparison between non-DC components in Fig. 15 and resonant frequencies in Fig. 13.

\begin{tabular}{c|cc}
\hline \multirow{2}{*}{ Converter current } & \multicolumn{2}{|c}{ Frequency of Non-DC Components $[\mathrm{Hz}]$} \\
\cline { 2 - 3 } & $\begin{array}{c}\text { Time Domain } \\
\text { (Fig. 15) }\end{array}$ & $\begin{array}{c}\text { Frequency Domain } \\
\text { (Fig. 13) }\end{array}$ \\
\hline \multirow{3}{*}{$i_{C-A}$} & 4.5 & 4.5 \\
& 7 & 8 \\
& 14 & 14.7 \\
& 70 & 71 \\
\hline \multirow{3}{*}{$i_{C-B}$} & 7 & 8 \\
& 11.5 & 12 \\
$i_{C-C}$ & 91 & 90 \\
\hline \multirow{3}{*}{$i_{C-D}$} & 14 & 14.3 \\
& 73 & 71 \\
& 94 & 95 \\
\hline \multirow{2}{*}{$i_{C-E}$} & 7 & 8 \\
& 13.5 & 14.5 \\
\hline
\end{tabular}
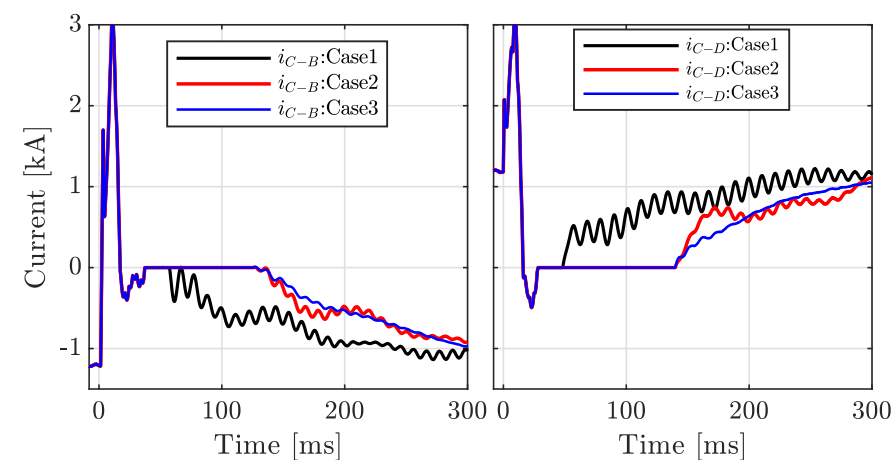

Fig. 16: DC-terminal currents of C-B (left) and C-D (right), for the cases 1,2 and 3.

while $1 \mathrm{kHz}$ sampling frequency is used. $X_{1}$ is set to $15 \%$ as an illustrative example. It is important to note that $X_{1}$ can be reduced/increased, but then the de-blocking delay is increased/decreased.

De-blocking the converters based on the voltage evaluation criterion improves the HVDC grid restoration behavior in that the oscillatory behavior in voltages and currents is reduced (Figures 16 and 17). The black and red curves in Figures 16 and 17 show illustrative examples of the currents and voltages at the DC terminal of converters C-B and C-D during recovery process for the first two cases, respectively. Although converter de-blocking is delayed in Case 2 in comparison with Case 1 (68 $\mathrm{ms}$ for $\mathrm{C}-\mathrm{B}$ and $90 \mathrm{~ms}$ for C-D), the amplitude of the oscillations in Case 2 is lower compared with the oscillations in Case 1. The reason for this is that the recovery process occurs under conditions in which the initial voltage step, which triggers the oscillations, also has a lower amplitude (the initial voltage steps at the instant of de-blocking can be seen in the zoomed-in plots of the voltages in Fig. 17 (b)).

Case 3: Converters are de-blocked based on the voltage evaluation criterion in addition to the modified CCSC. The band-pass filter bandwidth is selected to cover all resonant frequencies of the grid, based on the DC-side resonance analysis. As the minimum and maximum resonant frequencies 


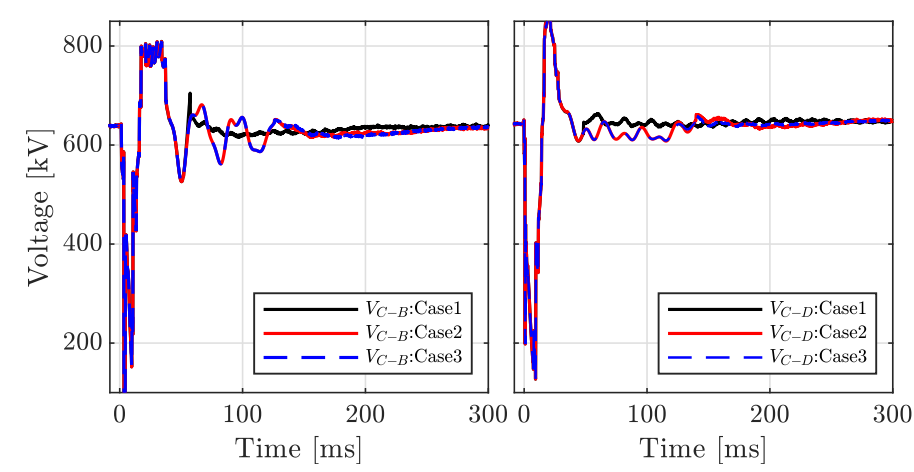

(a)

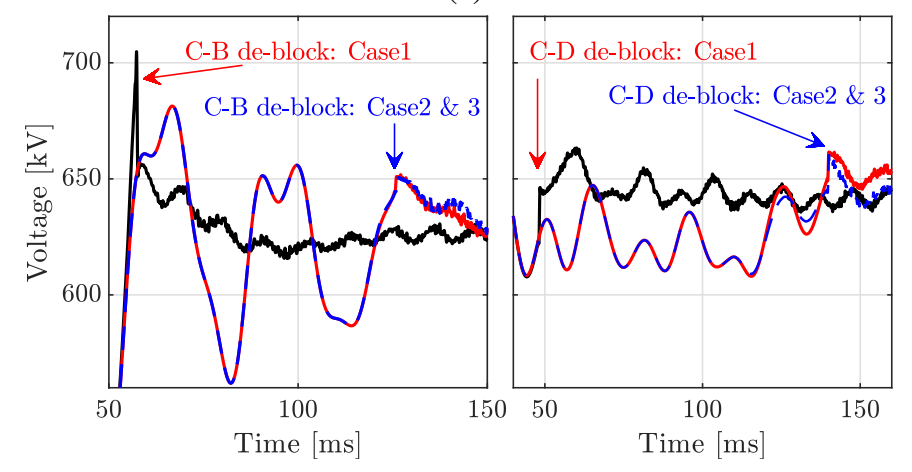

(b)

Fig. 17: (a) DC-terminal voltages of C-B (left) and C-D (right), (b) zoomed-in plots of the DC-terminal voltages of C-B (left) and C-D (right), for the cases 1, 2 and 3 .

with the lowest damping characteristic are 13 and $91 \mathrm{~Hz}$ for a line inductor value of $200 \mathrm{mH}$ (see Fig. 13), the bandwidth of the band-pass filter should be higher than $77 \mathrm{~Hz}$. Increasing the bandwidth of the band-pass filter to include lower frequencies will decrease the responsiveness of the DC-side controller to demands in active power.

The activation of the modified DQ-type CCSC in addition to the voltage evaluation criterion improves further the postfault recovery. The blue curves in Figures 16 and 17 show the recovery performance of Case 3 , where the DC quantities are restored with insignificant oscillations.

Case 4: De-blocking of the converters is delayed $300 \mathrm{~ms}$ after fault inception, to evaluate the voltage recovery when the voltage is much lower than the DC nominal voltage. The converters are de-blocked without activating any proposed method.

The amplitude of oscillations increases with increasing the mismatch between the DC nominal voltage and the DC-side voltage at the instant of de-blocking (Figures 18 and 19). Figures 18 and 19 compare the voltages and currents at the DC terminal of converters $\mathrm{C}-\mathrm{B}$ and $\mathrm{C}-\mathrm{D}$ during recovery process for the last three cases. The black curves in Figures 18 and 19 show the currents and voltages at the DC terminal of converters C-B and C-D during recovery process for Case 4. Compared with the oscillations in Case 1 (black curves in Fig. 16), the oscillations in Case 4 has higher amplitudes due to the increase in the initial voltage step at the instant of deblocking (the initial voltage steps at the instant of de-blocking can be seen in the zoomed-in plots of the voltages (black

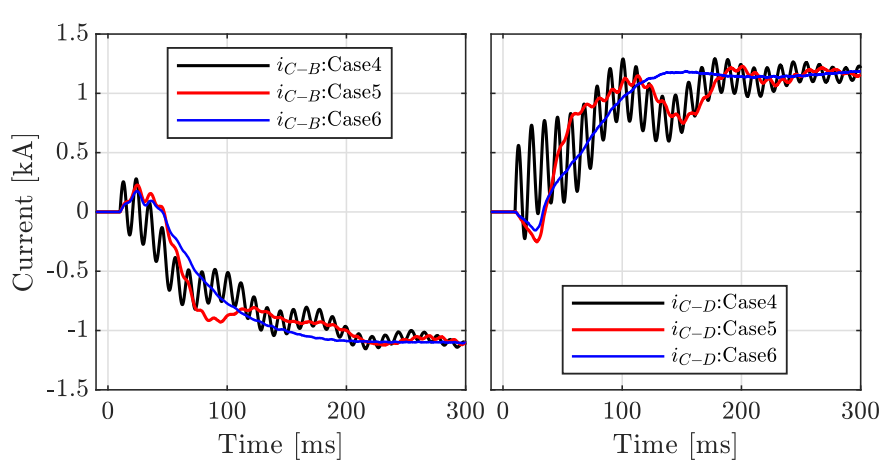

Fig. 18: (a) DC-terminal currents of C-B (left) and C-D (right), for the cases 4,5 and 6 .

curves) in Fig. 19 (b)).

Case 5: All parameters are the same as Case 4, except that the DC-side voltage reduction controller is now activated.

The DC-side voltage reduction controller proves to be effective in avoiding oscillations (red curves in Figures 18 and 19). The red curves in the zoomed-in figures of the DCside voltages (Fig. 19(b)) show that the generated voltage by the submodules match the DC-side voltage of the grid for Case 5, and increases to the pre-fault value, while the generated voltage in Case 4 is stepped to the pre-fault value as described previously. The step voltage in Case 4 triggers poorly damped oscillations (black line in Figures 18 and 19), whereas the oscillations are highly attenuated in Case 5 (red line). As in Case 2, the recovery process occurs under conditions in which the triggered oscillations do not take such high amplitudes.

Case 6: In addition to activating the DC-side voltage reduction controller, the modified DQ-type CCSC is also activated.

Further improvement in the recovery process can be achieved when the modified DQ-type CCSC is activated as shown in the blue curves in Figures 18 and 19, where the oscillations in the DC-side quantities almost disappear.

\section{CONCLUSiON}

In this paper, the behavior of HVDC grids during post-fault recovery process has been investigated, where the converters recovery may trigger poorly damped oscillations if no adequate countermeasures are considered. To limit the amplitude of the oscillations during post-fault recovery, two methods are proposed, where the first method aims to match the inserted DC-side voltage of the converter with the HVDC grid voltage at the instant of de-blocking, while the second method aims to add a damping component to the DC-side control of the MMC by modifying the DQ-type CCSC.

The post-fault recovery response of the HVDC grid and the parameters of the proposed methods can be evaluated and determined by the DC-side resonance analysis. Hence, this paper proposes a converter equivalent circuit, which can be used in an analytical approach to efficiently and accurately predict the values of the resonant frequencies and to investigate the influence of changing grid parameters (e.g. line inductor value) on the frequency response of the grid. 


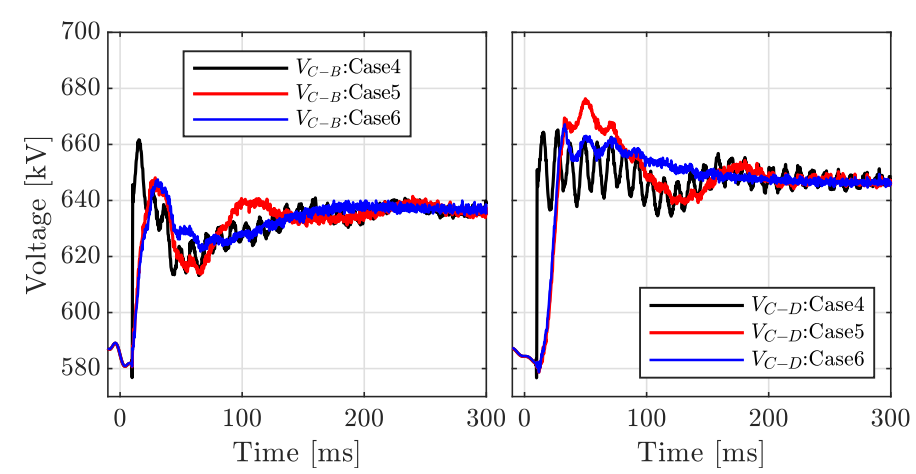

(a)

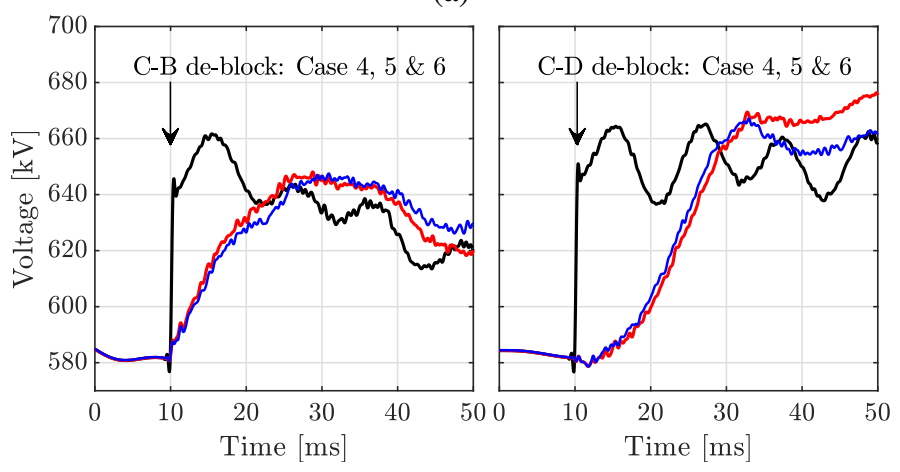

(b)

Fig. 19: (a) DC-terminal voltages of C-B (left) and C-D (right), (b) zoomed-in plots of the DC-terminal voltages of C-B (left) and C-D (right), for the cases 4,5 and 6.

Although the proposed voltage matching method may result in an increased delay of converters de-blocking after fault clearance, it prevents triggering or minimizes the oscillations in the grid. Furthermore, the implementation of the modified DQ-type CCSC in addition to voltage matching methods improves the system performance during the recovery process with highly attenuated DC-side oscillations.

\section{APPENDIX}

\section{A. Derivation of Converter DC-Side Equivalent Impedance}

The dynamics of the MMC are described by a third order system as shown in (13) [24], with the state variables $v_{c}^{\Sigma k}$ (summation of the capacitors voltages in the $k^{t h}$ leg), $v_{c}^{\Delta k}$ (unbalance capacitor voltage between the upper and lower arms in the $k^{t h}$ leg) and $i_{c}^{k}$ (circulating current). The arms inductance and resistance are described by $L_{a r m}$ and $R_{a r m}$, respectively, while $C_{s u b}$ is the submodule capacitor value and $N$ is the number of submodules per arm. The variables $v_{s}^{* k}$, $i_{s}^{* k}$ and $v_{c}^{* k}$ are the reference values of the output AC voltage, $\mathrm{AC}$ current and internal voltage, respectively.

$$
\begin{aligned}
\frac{C_{s u b}}{N} \frac{d v_{c}^{\Sigma k}}{d t} & =-\frac{v_{s}^{* k} i_{s}^{k}}{v_{d c}}+\left(1-\frac{2 v_{c}^{* k}}{v_{d c}}\right) i_{c}^{k} \\
\frac{C_{s u b}}{N} \frac{d v_{c}^{\Delta k}}{d t} & =\left(1-\frac{2 v_{c}^{* k}}{v_{d c}}\right) \frac{i_{s}^{*}}{2}-\frac{2 v_{s}^{* k} i_{c}^{k}}{v_{d c}} \\
L_{a r m} \frac{d i_{c}^{k}}{d t} & =\frac{v_{d c}}{2}-\frac{v_{c}^{\Sigma k}}{4}+\frac{v_{c}^{* k} v_{c}^{\Sigma k}}{2 v_{d c}}+\frac{v_{s}^{* k} v_{c}^{\Delta k}}{2 v_{d c}}-R_{a r m} i_{c}^{k}
\end{aligned}
$$

By rearranging the summation of the dynamic equations in (13c) of the three MMC legs, (14) is obtained.

$$
\begin{aligned}
v_{d c}= & \frac{2}{3} L_{a r m} \frac{d i_{d c}}{d t}+\frac{2}{3} R_{a r m} i_{d c}+\frac{1}{6} \sum_{k=a, b, c} v_{c}^{\Sigma k} \\
& -\frac{1}{3} \sum_{k=a, b, c} \frac{v_{c}^{* k} v_{c}^{\Sigma k}}{v_{d c}}-\frac{1}{3} \sum_{k=a, b, c} \frac{v_{s}^{* k} v_{c}^{\Delta k}}{v_{d c}}
\end{aligned}
$$

1) Derivation of $3^{\text {rd }}$ term in (14): Assuming that $v_{s}^{* k}$ and $i_{s}$ are controlled to the quantities described in (15), where $\phi$ is the phase shift between $v_{s}^{* k}$ and $i_{s}^{k}$, and $\theta=0, \frac{2 \pi}{3}$ or $\frac{-2 \pi}{3}$ for $k=a, b$ or $c$, respectively, and substituting these quantities in (13a), the dynamic equation of $v_{c}^{\Sigma}$ for phase $k$ can be found in (16).

$$
\begin{gathered}
v_{s}^{* k}=V_{s} \cos (\omega t+\theta) \\
i_{s}=I_{s} \cos (\omega t+\theta-\phi) \\
\frac{C_{s u b}}{N} \frac{d v_{c}^{\Sigma k}}{d t}=-\frac{V_{s} I_{s} \cos (\phi)}{2 v_{d c}}-\frac{V_{s} I_{s} \cos (2 \omega t+\theta-\phi)}{2 v_{d c}} \\
+\left(1-\frac{2 v_{c}^{* k}}{v_{d c}}\right) i_{c}^{k}
\end{gathered}
$$

The circulating current $\left(i_{c}^{k}\right)$ consists of AC and DC components as described in (17), where $\theta_{i_{c c}}^{k}$ is the angle of $i_{c}^{k}$. Furthermore, the internal voltage reference $\left(v_{c}^{* k}\right)$ is determined by the output of the CCSC, where $v_{c}^{* k}$ is decomposed of $\mathrm{AC}$ and DC components as shown in (18), depending on the implemented CCSC type. The term $\theta_{v_{c c}}^{k}$ is the angle of $v_{c}^{* k}$.

$$
\begin{aligned}
i_{c}^{k}= & \frac{\bar{I}_{d c}}{3}+I_{c} \cos \left(2 \omega t+\theta_{i_{c c}}^{k}\right) \\
& +\sum_{n>2} A_{i} \cos \left(n \omega t+\theta_{i}^{k}\right) \\
v_{c}^{* k}= & V_{c}^{* 0}+V_{c} \cos \left(2 \omega t+\theta_{v_{c c}}^{k}\right) \\
& +\sum_{n>2} A_{v} \cos \left(n \omega t+\theta_{v}^{k}\right)
\end{aligned}
$$

By substituting (17) and (18) in (16), and taking phase $a$ as an example, the dynamic equation of $v_{c}^{\Sigma a}$ can be rewritten as follows:

$$
\begin{aligned}
\frac{C_{s u b}}{N} \frac{d v_{c}^{\Sigma a}}{d t} & =-\frac{V_{s} I_{s} \cos (\phi)}{2 v_{d c}}-\frac{V_{s} I_{s} \cos (2 \omega t-\phi)}{2 v_{d c}}+\alpha+\beta+\gamma+\zeta, \\
\text { where } \alpha & =\frac{\bar{I}_{d c}}{3}+I_{c} \cos \left(2 \omega t+\theta_{c c}-\phi_{c c}\right)+\sum_{n>2} A_{i} \cos \left(n \omega t+\theta_{a}\right), \\
\beta & =-\frac{\bar{I}_{d c}}{3}\left(\frac{2 v_{c}^{* a}}{v_{d c}}\right), \gamma=-I_{c} \cos \left(2 \omega t+\theta_{c c}-\phi_{c c}\right)\left(\frac{2 v_{c}^{* a}}{v_{d c}}\right), \\
\zeta & =-\sum_{n>2} A_{i} \cos \left(n \omega t+\theta_{a}\right)\left(\frac{2 v_{c}^{* a}}{v_{d c}}\right)
\end{aligned}
$$

The summation of the dynamic equations of $v_{c}^{\Sigma k}$ for the three-phase converter results in cancellation of the positive and negative sequence components as shown in (20), where $i_{d c}$ is decomposed of the DC component in addition to the zerosequence components, which circulate between the converter 
and the HVDC grid. The non-zero components resulted from this summation in $\beta, \gamma$ and $\zeta$ are ignored, as these components are divided by the DC voltage $\left(v_{d c}\right)$, which is much higher than $V_{c}^{0 *}, V_{c}, A_{i}$ and $A_{v}$. Furthermore, $I_{c}$ converges to zero due to the CCSC.

$$
\begin{aligned}
\frac{C_{s u b}}{N} \sum_{k=a, b, c} \frac{d v_{c}^{\Sigma k}}{d t} & =-\frac{3 V_{s} I_{s} \cos (\phi)}{2 v_{d c}}+i_{d c}, \\
\text { where } i_{d c} & =\bar{I}_{d c}+\sum_{n \neq 2} A_{i}^{0} \cos \left(n \omega t+\theta_{0}\right)
\end{aligned}
$$

The Laplace transform of the dynamic equation in (20) is given in (21), where $V_{c}^{\Sigma k}(0)$ is the initial condition of $v_{c}^{\Sigma k}$, which is equal to $V_{d c}^{\Sigma c}(0)$. Hence, (21) can be rewritten as shown in (22).

$$
\begin{aligned}
\frac{C_{s u b}}{N}\left(\sum_{k=a, b, c}\left(s V_{c}^{\Sigma k}(s)-V_{c}^{\Sigma k}(0)\right)\right) \\
=-\mathscr{L}\left\{\frac{3 V_{s} I_{s} \cos (\phi)}{2 v_{d c}}\right\}+I_{d c}(s)
\end{aligned}
$$

$$
\begin{aligned}
\sum_{k=a, b, c} V_{c}^{\Sigma k}(s) & =\frac{3 V_{d c}^{\Sigma}(0)}{s} \\
& -\frac{1}{s} \mathscr{L}\left\{\frac{3 N V_{s} I_{s} \cos (\phi)}{2 v_{d c} C_{s u b}}\right\}+\frac{N I_{d c}(s)}{s C_{s u b}}
\end{aligned}
$$

2) Derivation of $4^{\text {th }}$ term in (14): The term $v_{c}^{\Sigma k}$ consists of a DC component, an AC component with twice the fundamental frequency [24] and higher harmonics as described in (23).

$$
\begin{aligned}
v_{c}^{\Sigma k}= & V_{c}^{\Sigma d c}+V_{c}^{\Sigma \omega_{2}} \cos \left(2 \omega t+\theta_{c}^{\Sigma k}\right) \\
& +\sum_{n>2} A_{c}^{\Sigma} \cos \left(n \omega t+\theta_{n}^{\Sigma k}\right)
\end{aligned}
$$

The fourth term in (14) can be derived by substituting (18) and (23) in (24) for the three phases, where $A_{v}$ and $A_{c}^{\Sigma}$ in (18) and (23) are assumed to be insignificant and ignored.

$$
\begin{aligned}
\sum_{k=a, b, c} \frac{v_{c}^{* k} v_{c}^{\Sigma k}}{v_{d c}} & =\frac{\chi V_{c} V_{c}^{\Sigma \omega_{2}}}{2 v_{d c}}+\xi V_{c}^{* 0}, \\
\text { where } \chi & =\sum_{k=a, b, c} \cos \left(\theta_{c}^{\Sigma k}-\theta_{v_{c c}}^{k}\right), \\
\text { and } \xi & =\frac{3 V_{c}^{\Sigma d c}}{v_{d c}}
\end{aligned}
$$

3) Derivation of $5^{\text {th }}$ term in (14): The term $v_{c}^{\Delta k}$ has a DC component in addition to an AC component with the fundamental frequency [24] as described in (25).

$$
\begin{aligned}
v_{c}^{\Delta k} & =V_{c}^{\Delta d c}+V_{c}^{\Delta \omega_{1}} \cos \left(\omega t+\theta_{c}^{\Delta k}\right) \\
& +\sum_{n>2} A_{c}^{\Delta} \cos \left(n \omega t+\theta_{n}^{\Delta k}\right)
\end{aligned}
$$

The fifth term in (14) can be derived by substituting $v_{s}^{* k}$ and (25) in (26) for the three phases, where $A_{c}^{\Delta}$ in (25) is assumed to be insignificant and ignored.

$$
\begin{aligned}
\sum_{k=a, b, c} \frac{v_{s}^{* k} v_{c}^{\Delta k}}{v_{d c}} & =\frac{\Gamma V_{s} V_{c}^{\Delta \omega_{1}}}{2 v_{d c}}, \\
\text { where } \Gamma & =\sum_{k=a, b, c} \cos \left(\theta_{c}^{\Delta k}-\theta\right),
\end{aligned}
$$

By transforming (14) into Laplace domain, and substituting the Laplace transform of (20) (i.e. (22)), (24) and (26) in the resulting equation, $V_{d c}(s)$ can be found in (27).

$$
\begin{aligned}
V_{d c}(s)= & \frac{1}{6}\left(\frac{3 V_{d c}^{\Sigma}(0)}{s}-\frac{1}{s} \mathscr{L}\left\{\frac{3 N V_{s} I_{s} \cos (\phi)}{2 v_{d c} C_{s u b}}\right\}+\frac{N I_{d c}(s)}{s C_{s u b}}\right) \\
& +\frac{2}{3} L_{a r m}\left(s I_{d c}(s)-i_{d c}(0)\right)+\frac{2}{3} R_{a r m} I_{d c}(s) \\
& -\mathscr{L}\left\{\frac{\Gamma V_{s} V_{c}^{\Delta \omega_{1}}}{6 v_{d c}}+\frac{\chi V_{c} V_{c}^{\Sigma \omega_{2}}}{6 v_{d c}}+\frac{1}{3} \xi V_{c}^{* 0}\right\}
\end{aligned}
$$

The DC-side voltage of the converter $\left(V_{d c}(s)\right)$ can be simplified and written in terms of the DC-side current $\left(I_{d c}(s)\right)$, the power balance between the AC and the DC sides $(\eta)$ and the zero-sequence component of the internal voltage of the converter $\left(V_{c}^{* 0}(s)\right)$ as shown in (28), where the terms $\Gamma V_{s} V_{c}^{\Delta \omega_{1}}$, and $\chi V_{c} V_{c}^{\Sigma \omega_{2}}$ shown in (27) are ignored, as they are much smaller than $6 v_{d c}$.

$$
\begin{aligned}
V_{d c}(s)= & \frac{1}{6}(\frac{3 V_{d c}^{\Sigma}(0)}{s}-\underbrace{\frac{1}{s} \mathscr{L}\left\{\frac{3 N V_{s} I_{s} \cos (\phi)}{2 v_{d c} C_{s u b}}\right\}}_{\eta}+\frac{N I_{d c}(s)}{s C_{s u b}}) \\
& +\frac{2}{3} L_{a r m}\left(s I_{d c}(s)-i_{d c}(0)\right) \\
& +\frac{2}{3} R_{a r m} I_{d c}(s)-\frac{1}{3} \xi V_{c}^{* 0}(s)
\end{aligned}
$$

\section{B. HVDC Cable Configuration}

TABLE III: Parameters of HVDC cable system.

\begin{tabular}{lcccc}
\hline & $\begin{array}{c}\text { Outer Radius } \\
{[\mathrm{mm}]}\end{array}$ & $\rho[\Omega \mathrm{m}]$ & $\epsilon_{r}$ & $\mu_{r}$ \\
\hline Core & 19.5 & $1.7 \times 10^{-8}$ & - & 1 \\
Insulation 1 & 48.7 & - & 2.3 & 1 \\
Sheath & 51.7 & $22 \times 10^{-8}$ & - & 1 \\
Insulation 2 & 54.7 & - & 2.3 & 1 \\
Armour & 58.7 & $18 \times 10^{-8}$ & - & 10 \\
Insulation 3 & 63.7 & - & 2.3 & 1 \\
\hline
\end{tabular}

\section{REFERENCES}

[1] D. Van Hertem and M. Ghandhari, "Multi-terminal VSC HVDC for the European Supergrid: Obstacles," Renewable and Sustainable Energy Reviews, vol. 14, no. 9, pp. 3156-3163, 2010.

[2] H. Rao, "Architecture of nan'ao multi-terminal vsc-hvdc system and its multi-functional control," CSEE Journal of Power and Energy Systems, vol. 1, no. 1, pp. 9-18, March 2015.

[3] W. Zhou, X. Wei, S. Zhang, G. Tang, Z. He, J. Zheng, Y. Dan, and C. Gao, "Development and test of a $200 \mathrm{kV}$ full-bridge based hybrid HVDC breaker," in Proc. EPE'15 ECCE-Europe, Geneva, Switzerland, 2015, 7 pages. 


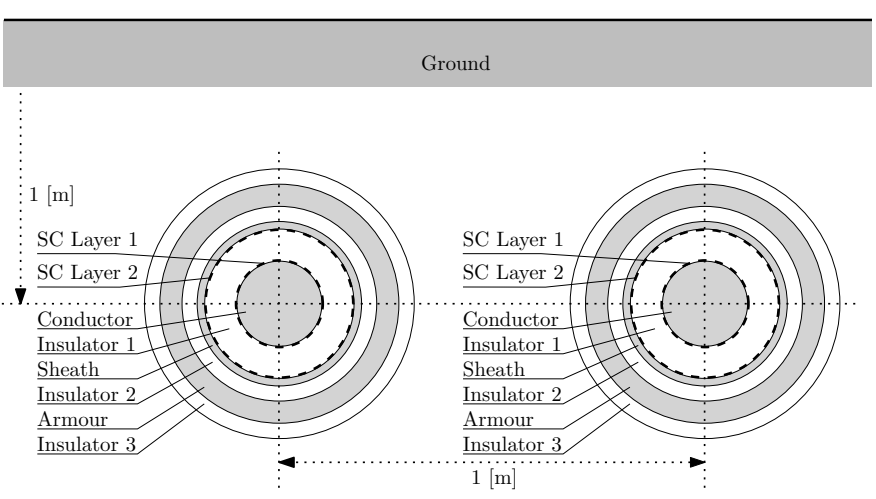

Fig. 20: HVDC Cable Configuration.

[4] M. Callavik, A. Blomberg, J. Häfner, and B. Jacobson, "The Hybrid HVDC Breaker: An innovation breakthrough enabling reliable HVDC grids," Tech. Rep., 2012.

[5] T. Eriksson, M. Backman, and S. Halen, "A low loss mechanical HVDC breaker for HVDC Grid applications," in Proc. Cigré Session, Paris, France, 2014, 8 pages.

[6] K. Tahata, S. E. Oukaili, K. Kamei, D. Yoshida, Y. Kono, R. Yamamoto, and H. Ito, "HVDC circuit breakers for HVDC grid applications," in Proc. IET ACDC 2015, Birmingham, UK, 2015, 9 pages.

[7] M. Abedrabbo, W. Leterme, and D. Van Hertem, "Systematic Approach to HVDC Circuit Breaker Sizing," IEEE Trans. Power Del., 2019, 13 pages.

[8] B. Chang, O. Cwikowski, M. Barnes, and R. Shuttleworth, "Multiterminal VSC-HVDC Pole-to-pole Fault Analysis and Fault Recovery Study," in Proc. IET ACDC 2015, Feb 2015, 8 pages.

[9] O. Cwikowski, A. Wood, A. Miller, M. Barnes, and R. Shuttleworth, "Operating DC Circuit Breakers With MMC," IEEE Trans. Power Del., vol. 33, no. 1, pp. 260-270, 2018.

[10] O. Cwikowski, H. R. Wickramasinghe, G. Konstantinou, J. Pou, M. Barnes, and R. Shuttleworth, "Modular Multilevel Converter DC Fault Protection," IEEE Trans. Power Del., vol. 33, no. 1, pp. 291-300, Feb 2018.

[11] J. Pou, S. Ceballos, G. Konstantinou, V. G. Agelidis, R. Picas, and J. Zaragoza, "Circulating Current Injection Methods Based on Instantaneous Information for the Modular Multilevel Converter," IEEE Trans. Industrial Electronics, vol. 62, no. 2, pp. 777-788, Feb 2015.

[12] T. Li and C. Zhao, "Recovering the modular multilevel converter from a cleared or isolated fault," IET Generation, Transmission Distribution, vol. 9, no. 6, pp. 550-559, 2015.

[13] W. Wang, M. Barnes, O. Marjanovic, and O. Cwikowski, "Impact of DC Breaker Systems on Multiterminal VSC-HVDC Stability," IEEE Trans. on Power Del., vol. 31, no. 2, pp. 769-779, April 2016.

[14] Q. Tu, Z. Xu, and J. Zhang, "Circulating current suppressing controller in modular multilevel converter," in Proc. IECON 2010, Nov 2010, pp. 3198-3202.

[15] X. She, A. Huang, X. Ni, and R. Burgos, "AC circulating currents suppression in modular multilevel converter," in Proc. IECON 2012, Oct 2012, pp. 191-196.

[16] Zheng Xu and Hongtao Liu, "The harmonic model and its algorithm for coupled multiphase transmission line," in Proc. 9'th Int. Conf. Harmonics Qual. Power, vol. 3, Oct 2000, pp. 938-941.

[17] Jan Machowski, Janusz W. Bialek, James R. Bumby, Power System Dynamics: Stability and Control. UK: John Wiley \& Sons, 2008.

[18] John J. Grainger, William D. Stevenson, Power System Anlaysis. USA: McGraw-Hill, 1994, ch. The Admittance Model and Network Calculations.

[19] F. Z. Dejene, M. Abedrabbo, J. Beerten, and D. Van Hertem, "Design of a DC Fault Current Reduction Control for Half-Bridge Modular MultiLevel Converters," in Proc. EPE'18 ECCE-Europe, Riga, Latvia, 2018, 9 pages.

[20] K. Sharifabadi, L. Harnefors, H.-P. Nee, S. Norrga, and R. Teodorescu, Design, control, and application of modular multilevel converters for HVDC transmission systems. UK: John Wiley \& Sons, 2016.

[21] “CIGRE-PSCAD MMC Model," https://hvdc.ca/knowledge-base/read, article/234/modular-multi-level-converter-mmc/v:

[22] Z. Zhang, Z. Xu, Y. Xue, and G. Tang, "DC-Side Harmonic Currents Calculation and DC-Loop Resonance Analysis for an LCCMMC Hybrid
HVDC Transmission System," IEEE Trans. Power Del., vol. 30, no. 2, pp. 642-651, April 2015.

[23] R. Dantas, J. Liang, C. E. Ugalde-Loo, A. Adamczyk, C. Barker, and R. Whitehouse, "Progressive Fault Isolation and Grid Restoration Strategy for MTDC Networks," IEEE Trans. Power Del., vol. 33, no. 2, pp. 909-918, 2018.

[24] L. Harnefors, A. Antonopoulos, S. Norrga, L. Angquist, and H. Nee, "Dynamic analysis of modular multilevel converters," IEEE Trans. Industrial Elec., vol. 60, no. 7, pp. 2526-2537, July 2013.

Mudar Abedrabbo (S'16) received the B.Sc. degree in electrical engineering from Birzeit University, Birzeit, Palestine, in 2009 and the M.Sc. degree in electrical power engineering from RWTH Aachen University, Aachen, Germany in December 2014. He is currently working toward the Ph.D. degree at KU Leuven, Leuven, Belgium. He was an Electrical Engineer with Petrofac International Ltd., Sharjah, UAE from 2009 to 2012. His main research interests are protection of HVDC transmission, modular multi-level converters and renewable energy integration.

Firew Zerihun Dejene (S'17) received M.Sc. degree in electrical power engineering from The Royal Institute of Technology, Stockholm, Sweden, in 2008. He worked as HVDC system design engineer in ABB AB, Ludvika, Sweden between 2010 and 2016. He is currently working toward the Ph.D. degree at KU Leuven University, Leuven, Belgium. His research interests include, power system dynamics and stability, modeling and control of VSCHVDC based systems for HVDC grid protection applications.

Willem Leterme (S'12-M'16) received the M.Sc. and Ph.D. degrees in electrical energy engineering from KU Leuven, Leuven, Belgium, in 2012 and 2016, respectively. He is currently a Research Expert with KU Leuven/EnergyVille. In 2015, he visited the University of Manchester as a Ph.D. student, and in 2018, he was with Imperial College London as a Visiting Postdoctoral Researcher, where both visits were funded by the Research FoundationFlanders. His research interests include power system protection and modeling for electromagnetic transient studies with a focus on HVDC systems. He is a member of the International Council on Large Electric Systems (CIGRÉ).

Dirk van Hertem (S'02-SM'09) graduated as a M.Eng. in 2001 from KHK, Geel, Belgium and as a M.Sc. in Electrical Engineering from KU Leuven, Leuven, Belgium in 2003. In 2009, he has obtained his Ph.D. degree from KU Leuven in 2009. In 2010, he was a member of EPS group with The Royal Institute of Technology, Stockholm, Sweden. Since spring 2011 he is back at KU Leuven where he is an associate professor in ELECTA group. His fields of interest are power system operation and control in systems with FACTS and HVDC and the transmission system of the future, including offshore grids and the supergrid. He is an active member of the IEEE PES, IAS, and CIGRÉ. 